\title{
THE LOW TEMPERATURE PREPARATION OF ULTRA LOW-DENSITY CERAMIC PROPPANTS BY ADDING FLY ASH
}

\author{
XINWEI ZOU*, RUYUAN HOU*, JIANYING HAO*, GUOMIN LI*, KAIYUE WANG*, "YUMING TIAN*,** \\ *School of Materials Science and Engineering, Taiyuan University of Science and Technology, \\ Taiyuan 030024, PR China \\ **Shanxi Engineering Vocational College, \\ Taiyuan 030009, PR China \\ "E-mail: tym1654@126.com
}

Submitted August 19, 2019; accepted October 9, 2019

\begin{abstract}
Keywords: Ceramic proppant, Mullite, Fly ash, Low-density
Ultra low-density mullite-corundum based ceramic proppants were prepared from fly ash, bauxite, manganese dioxide and dolomite through a low temperature sintering method. The bulk density and breakage ratio of the proppants were systematically investigated as functions of the sintering temperature and the fly ash content. The morphology structure and phase composition of the different proppants were investigated by scanning electron microscopy and X-ray diffraction. The proppants were composed of corundum, prismatic mullite and glass phases. The fly ash introduction promoted the formation of prismatic mullite crystals at a lower sintering temperature. As the fly ash content increased, the prismatic mullite phase increased, but the apparent density decreased. The proppants containing $30 \mathrm{wt} . \%$ of fly ash and $65 \mathrm{wt} \%$ of alumina sintered at $1200{ }^{\circ} \mathrm{C}$ exhibited an apparent density of $2.47 \mathrm{~g} \cdot \mathrm{cm}^{-3}$ and a breakage ratio of $8.35 \%$ under $35 \mathrm{MPa}$. Such a low density and sintering temperature, with sufficient crush resistance strength, were due to the structure of the interlocked mullite and corundum phases.
\end{abstract}

\section{INTRODUCTION}

Hydraulic fracturing is an important technology to improve the production of oil and gas in a bearing formation, especially in a low permeability oil and gas well. In a hydraulic fracturing operation, the fracturing fluid and proppants are pumped at high pressure into the underground well over a distance of several kilometres. Then, the high-pressure fluid and proppants create fractures in the rock. When the hydraulic pressure is removed, the proppants remain in the fractures, keeping the fractures open and improving the hydrocarbon fracture conductivity [1]. A low-density proppant is preferred in most applications because it reduces the settling rate of the proppant, only requires low fluid viscosity to transport it and also allows for an increased propped length $[2,3]$. Thus, several techniques have been developed to reduce the density of the proppant.

A simple and straightforward way to prepare a lowdensity proppant is to select low-density raw materials, such as polymers, walnut shells, pits, husks and the like [4]. However, the low structural strengths of these lighter materials limit their applications. Another way to reduce the density of the proppant is to incorporate a large amount of pores or voids into the material which has an inherently high strength $[3,5,6]$. Parse and Jette have developed low-density proppants that are made from hollow spheres and hollow closed-ended elongated particles, having a uniform and continuous wall composed of single or multiple component materials from glass, ceramics, metals, metal oxides, or a combination such that the particle has a neutral buoyancy or substantively neutral buoyancy while retaining its structural integrity against hydrostatic or contact loading [7,8].

Fly ash is a by-product of coal-fired thermal power plants. If not treated properly, fly ash can cause water and soil pollution, consequently disrupting the ecological cycle. About $56 \%$ of fly ash is effectively utilised through cement, bricks \& tiles, land reclamation, mine filling and other methods, and the remaining fly ash is still a concern to society [9]. Much attention is focused on the commercial applications like the replacement of cement and bricks. This process not only consumes the generated industrial wastes but also reduces the cost. The chemical composition of fly ash is very similar to that of traditional ceramic raw materials, so it is also suitable for the preparation of ceramics. Therefore, the comprehensive utilisation of fly ash to produce ceramic materials could be of great practical significance. A lot of research work has been undertaken on the recycling and utilisation of fly ash in the preparation of glass-ceramics with controllable crystalline phases [10], cordierite ceramics [11], and a porous cordierite membrane where both a layered porous micro-structure and multi-oxide crystalline phase could be effectively controlled at the one-step reaction sintering process $[12,13]$. Recently, $\mathrm{Xu}$ et al. reported that a mullite whisker network reinforced ceramic with a high strength of $190.10 \mathrm{MPa}$ and low 
density of $1.48 \mathrm{~g} \cdot \mathrm{cm}^{-3}$ can be successfully synthesised by adding fly ash [14]. Wu et al. reported that low-density and high-strength ceramic proppants prepared using fly ash have a $5.0 \%$ breakage ratio under $52 \mathrm{MPa}$ and the apparent density is $2.61 \mathrm{~g} \cdot \mathrm{cm}^{-3}$ [15]. These previous studies indicate that fly ash is quite suitable for the preparation of low-density mullite ceramic proppants. However, the sintering temperature for the preparation of these ceramic proppants from fly ash is relatively high, more than $1300{ }^{\circ} \mathrm{C}$. Low-temperature sintering is quite an important method to reduce the fabrication costs of ceramic proppants. In order to lower the sintering temperature, a great deal of research has been made to obtain a dense mullite by the liquid-phase process with different sintering aids such as $\mathrm{CaO}, \mathrm{MnO}_{2}$ and $\mathrm{TiO}_{2}[16-$ 18]. Therefore, it is necessary to adopt the appropriate sintering additive to lower the sintering temperature of the mullite strengthened proppants by the newly formed liquid phase, without the significant degradation of the other properties.

Herein, the low-density ceramic proppants were prepared from the main materials of fly ash and bauxite with $\mathrm{MnO}_{2}$ and dolomite as the sintering additives, and sintered at a low temperature below $1250{ }^{\circ} \mathrm{C}$. Furthermore, the effects of the fly ash content and sintering temperature on the bulk density, the breakage ratio, and the structural properties of the proppants were investigated.

\section{EXPERIMENTAL}

\section{Materials}

The fly ash came from a thermal power plant in Shanxi Province, China, containing 41.53 wt. \% $\mathrm{SiO}_{2}$, 37.38 wt. $\% \mathrm{Al}_{2} \mathrm{O}_{3}, 11.78$ wt. $\% \mathrm{C}$ and tiny amounts of $\mathrm{Fe}_{2} \mathrm{O}_{3}, \mathrm{CaO}$ and $\mathrm{K}_{2} \mathrm{O}$, etc. The bauxite ( 300 mesh) was produced in the area of Yangquan in Shanxi Province, China, mainly used for introduction of alumina, containing 56.06 wt. $\% \mathrm{Al}_{2} \mathrm{O}_{3}, 25.76$ wt. $\% \mathrm{SiO}_{2}, 0.41$ wt. $\% \mathrm{CaO}$, 2.15 wt. $\% \mathrm{TiO}_{2}, 1.24$ wt. $\% \mathrm{Fe}_{2} \mathrm{O}_{3}, 0.17$ wt. $\% \mathrm{Na}_{2} \mathrm{O}$, and $13.81 \mathrm{wt}$. \% loss on ignition. The dolomite was obtained from China's Yangquan Changqing Petroleum Proppant Co., Ltd., mainly containing 21.0 wt. \% MgO, 31.0 wt. $\% \mathrm{CaO}$ and $\sim 47.0$ wt. $\%$ loss on ignition. The $\mathrm{MnO}_{2}$ was of an analytical reagent grade and used as an additive.

\section{Preparation of the proppants}

According to certain proportions, the powder raw materials were mixed and ground with a planetary ball mill for $2 \mathrm{~h}$ to evenly mix it and achieve the desired particle size. In order to maximise the use of the industrial waste, the formulations with different fly ash contents were designed, as shown in Table 1. In the proppant formulation, the total content of the dolomite and $\mathrm{MnO}_{2}$ was 5.0 wt. $\%$ and the $\mathrm{MnO}_{2} /$ dolomite ratio was fixed at $2: 1$. After milling, one part of the fine powder mixture was put into a strong mixing machine (R02, Eirich Co. Ltd, Hardheim, Germany) and some water was added to make it grow into spherical cores of green proppant bodies. Then, in a rolling sugar film coating machine, the cores were coated with the fine powder to form spherical green bodies with a certain size. The green spheres were dried in a drying box (DH-101-2BS, Tianjin central experiment Furnace Co. Ltd, China) at $100{ }^{\circ} \mathrm{C}$ for 2 hours, then passed through a group of sieves of 20/40 meshes. The sieved green spheres were sintered in a Muffle furnace (KBF1700, Nanjing Bo Yun Tong Instrument Technology Co. Ltd, Nanjing, China) at a heating rate of $5^{\circ} \mathrm{C} \cdot \mathrm{min}^{-1}$, and the sintering temperatures were between $1170{ }^{\circ} \mathrm{C}$ and $1250{ }^{\circ} \mathrm{C}$. After sintering, it was cooled to $400{ }^{\circ} \mathrm{C}$ at a cooling rate of $5{ }^{\circ} \mathrm{C} \cdot \mathrm{min}^{-1}$, and then naturally cooled to the room temperature in the furnace. Finally, the cooled proppants were passed through the sieves of the 20/40 meshes again.

\section{Characterisation}

The apparent density $\left(\rho_{a}\right)$ was measured according to Archimedes' principle and calculated by the formula $\rho_{a}=M / V_{a}$, where $M$ is the weight of the proppants (g), $V_{a}$ is the apparent volume taking into consideration any voids $\left(\mathrm{cm}^{3}\right)$.

The breakage ratio $(\eta)$ of the proppant was determined according to the Chinese Petroleum and Gas Industry Standard (SY/T 5108-2014) in a steel cylinder. The diameter of the cylinder used for measuring the breakage ratio was $50.8 \mathrm{~mm}$, which conforms to the standard of $30.1 \mathrm{~mm} \sim 76.2 \mathrm{~mm}$. The test pressure was under $35 \mathrm{Mpa}$. The breakage ratio was calculated using the following formula $\eta=W_{c} / W_{0} \times 100 \%$, where $W_{c}$ and $W_{0}$ were the weights of the crushed specimens $(\mathrm{g})$ before and after testing, respectively.

The solubility in acids was also determined according to the SY/T 5108-2014 standard. In the experiment, first, $5 \mathrm{~g}\left(W_{s}\right)$ of the proppants was added into $100 \mathrm{ml}$ of a hydrochloric-hydrofluoric acid solution $(12 \mathrm{wt} . \% \mathrm{HCl}$ and $3 \mathrm{wt} . \% \mathrm{HF}$ ) and then the entire mixture was heated in a water bath at $65^{\circ} \mathrm{C}$ for $30 \mathrm{~min}$. After that, the proppants were washed with deionised water and dried in a drying box at $105{ }^{\circ} \mathrm{C}$ for $1 \mathrm{~h}$. After drying, the proppants were weighed and denoted by $W_{a}$, then the acid solubility $(S)$ was calculated based on the formula of

$$
S=\left(W_{s}-W_{a}\right) / W_{s} \times 100 \% .
$$

The crystalline phases of the sintered proppants were characterised by X-ray diffraction (XRD) using an "X'Pert PRO" multi-purpose X-ray diffractometer (PANalytical B.V., Almelo, Netherlands) with $\mathrm{Cu} \mathrm{K \alpha}$ radiation $(\mathrm{K} \alpha=1.5405 \AA)$ operated at a $40-\mathrm{kV}$ voltage and a 40-mA current. The morphology and microstructure of the as-prepared proppants were observed by Scanning Electron Microscopy (SEM) using a field emission 
scanning electron microscope (S-4800, Hitachi, Japan). To reveal the crystalline phase, the proppants were sputtered with a gold coating on the cross-sectional surfaces after being etched in a $12 \mathrm{wt} . \% \mathrm{HCl}$ and $3 \mathrm{wt} . \%$ $\mathrm{HF}$ solution for $10 \mathrm{~min}$. The chemical composition was estimated by Energy Dispersive X-ray Spectroscopy (EDS) equipment combined with the Scanning Electron Microscope.

\section{RESULTS AND DISCUSSION}

The breakage ratio and acid solubility are the key parameters to evaluate the proppant performance. Figure 1 shows the acid solubility and breakage ratio of the proppants sintered at the different temperatures for 2 hours with the different fly ash contents. It can be seen that the acid solubility and breakage ratio of the different proppants at first decreased and then increased as the sintering temperature increased. A higher sintering temperature can enhance the densifying process which gradually improves the performance [2]. However, when the sintering temperature exceeds a certain value or range, the optimal sintering temperature or the optimal sintering temperature range, the performance of the proppants degrades due to the abnormal growth and to the melting of the crystals as well as to the formation of more glass phases [15].

The main ingredients, sintering temperatures and

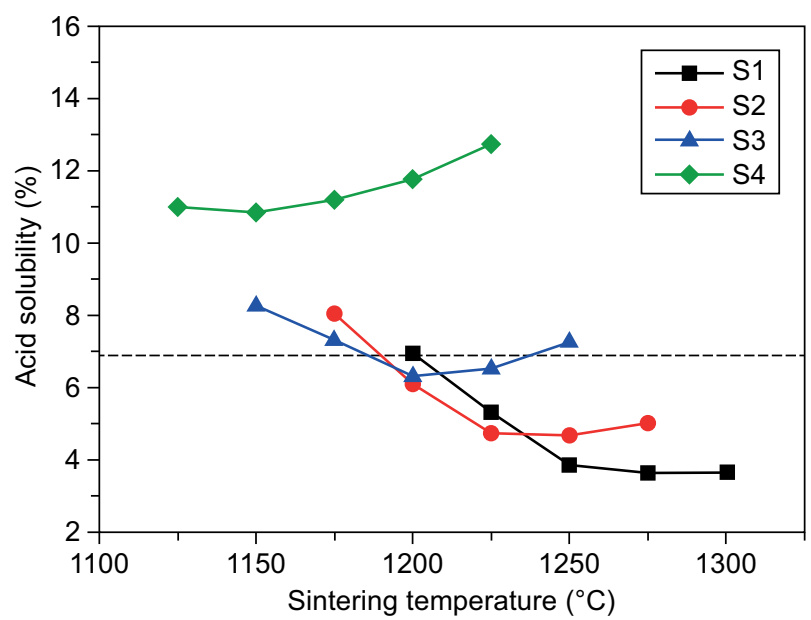

a) acid solubility performance parameters of the different proppants are shown in Table 1. The total content of dolomite and $\mathrm{MnO}_{2}$ as the mineralisers in the proppant formula is $5.0 \mathrm{wt} . \%$. It can be seen from Table 1 that when the fly ash content increases from $10 \mathrm{wt}$. $\%$ to $40 \mathrm{wt} . \%$ and the bauxite content decreases from 85 wt. $\%$ to 55 wt. $\%$, the $\mathrm{Al}_{2} \mathrm{O}_{3} / \mathrm{SiO}_{2}$ molar ratio, optimal sintering temperature and apparent density of the proppants decrease. However, the acid solubility and breakage ratio increase as the fly ash content increases. This may be due to the addition of more fly ash, forming more low temperature liquid glass phases. The formation of the glass phase promotes the sintering process, but it decreases the strength and corrosion resistance of the proppants.

According to the Chinese proppant industry standard of SY/T 5108-2014, the acid solubility value should be less than $7 \%$ and the breakage ratio should not be more than $10 \%$ as noted by the horizontal dash lines in Figure 1. It can be seen that all the performance parameters of the S4 proppants with a fly ash content of 40 wt. $\%$ do not meet the industry standards. The performance parameters of the S3 proppants sintered at more than $1200{ }^{\circ} \mathrm{C}$ with a fly ash content of $30 \mathrm{wt} . \%$ meet the industry standards. The performance parameters of the S1 and S2 proppants are all better than that of S3, but the sintering temperature is higher and the utilised fly ash is less. In addition, as can be seen from Figure 1, the acid solubility and breakage ratio of the $\mathrm{S} 1$ proppants always decrease as the sintering temperature increases.

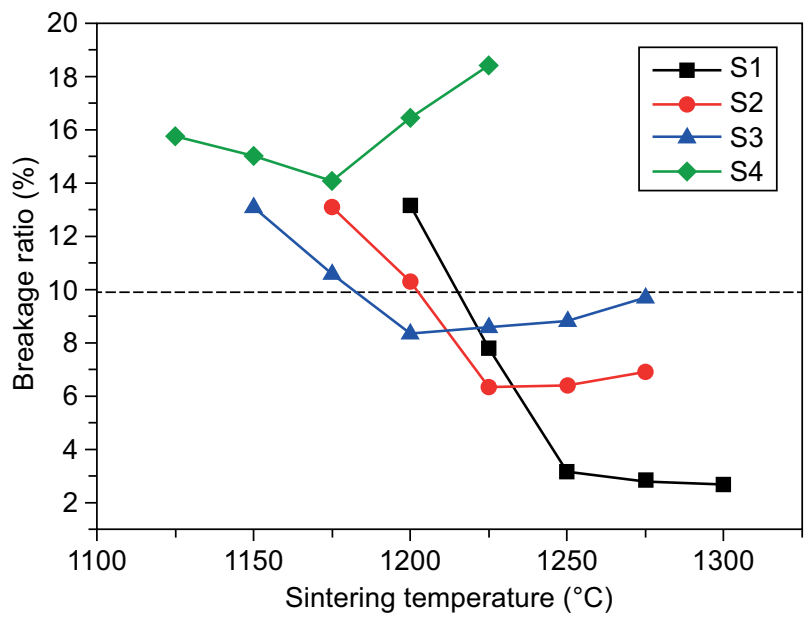

b) breakage ratio

Figure 1. The acid solubility (a) and the breakage ratio (b) of the proppants sintered at the different temperatures.

Table 1. The main contents and performance parameters of the different proppants.

\begin{tabular}{lccccccc}
\hline Sample & $\begin{array}{c}\text { Fly ash } \\
(\text { wt. \%) }\end{array}$ & $\begin{array}{c}\text { Bauxite } \\
(\text { wt. \%) }\end{array}$ & $\begin{array}{c}\mathrm{Al}_{2} \mathrm{O}_{3} / \mathrm{SiO}_{2} \\
\text { molar ratio } \\
(\%)\end{array}$ & $\begin{array}{c}\text { Best sintering } \\
\text { temperature } \\
\left({ }^{\circ} \mathrm{C}\right)\end{array}$ & $\begin{array}{c}\text { Breakage } \\
\text { ratio } \\
(\%)\end{array}$ & $\begin{array}{c}\text { Acid } \\
\text { solubility } \\
(\%)\end{array}$ & $\begin{array}{c}\text { Apparent } \\
\text { density } \\
\left(\mathrm{g} \cdot \mathrm{cm}^{-3}\right)\end{array}$ \\
\hline $\mathrm{S} 1$ & 10 & 85 & 1.16 & 1250 & 3.16 & 3.83 & 2.66 \\
$\mathrm{~S} 2$ & 20 & 75 & 1.08 & 1225 & 6.34 & 4.74 & 2.54 \\
$\mathrm{~S} 3$ & 30 & 65 & 0.96 & 1200 & 8.35 & 6.32 & 2.47 \\
S4 & 40 & 55 & 0.92 & 1175 & 14.08 & 10.85 & 2.21 \\
\hline
\end{tabular}


This is probably due to the sintering temperature being lower than the optimal sintering temperature of S1 for its more bauxite and less fly ash contents. This means the acceptable value of the fly ash content was $30 \mathrm{wt} . \%$. Furthermore, the optimal sintering temperature of S3 is $1200{ }^{\circ} \mathrm{C}$, which is significantly lower than conventional sintering temperatures (typically from $1300{ }^{\circ} \mathrm{C}$ to $\left.1600{ }^{\circ} \mathrm{C}\right)$.

In order to recycle and utilise the industrial waste fly ash as much as possible and reduce the production cost, the S3 proppants were selected for further study for the relatively high fly ash content and relatively low sintering temperature. On the basis of the S3 formula, the apparent density, sintering temperature and breakage ratio, as well as other properties, were further studied. The S3 proppants tend to bond together at sintering temperatures exceeding $1200{ }^{\circ} \mathrm{C}$, which can be ascribed to the formation of too much of the low-temperature liquid phase formed beyond this sintering temperature. Therefore, the optimal sintering temperature was determined to be $1200{ }^{\circ} \mathrm{C}$. Figure 2 shows the relationship between the apparent density of the S3 proppants and the sintering time. The sintering temperature was fixed at $1200{ }^{\circ} \mathrm{C}$. The apparent density first increases with the sintering time and then it decreases. When the sintering time is $150 \mathrm{~min}$, the apparent density is the maximum. Subsequently, the apparent density decreases with an increasing temperature. Figure 2 also shows that with an increase in the sintering time, the breakage ratio of S3 first declines and then rises. When the sintering time is $120 \mathrm{~min}$, the minimum value of the breakage ratio is $8.35 \%$. Generally, the higher the proppant density, the stronger the crushing resistance is. However, as shown in Figure 2, it is not the proppant with the highest apparent density that is the most resistant to the crushing. This may be due to the phase structure and the microstructure characteristics. The porosity of the proppants prepared by the pressure-less sintering is inevitable, and the high porosity is known to reduce the load area and concentrate the stress at the edges of the pores [19]. Therefore, the

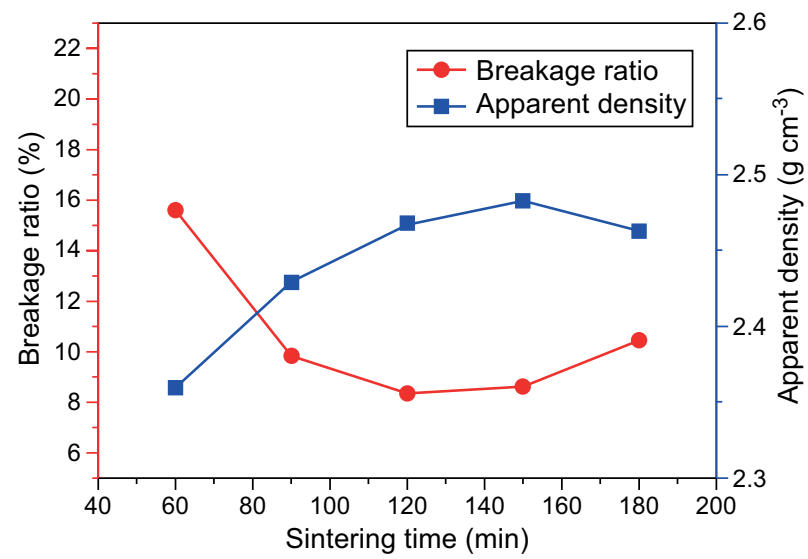

Figure 2. The apparent density and breakage ratio of the S3 proppants sintered for the different times. elimination of the pores can increase the density of the proppants and improve the crushing resistance of the proppants. The S3 proppant sintered for $120 \mathrm{~min}$ has the lowest breakage ratio while its apparent density is not the highest. The breakage ratio and the apparent density of the S3 proppants sintered for $150 \mathrm{~min}$ and $180 \mathrm{~min}$ are higher than that of S3 sintered for $120 \mathrm{~min}$. This can be attributed to the fact that the S3 proppants sintered for $150 \mathrm{~min}$ and $180 \mathrm{~min}$ have large fractions of the glass phase, which has a low crushing resistance strength, but can decrease the porosity. Generally, the low-density proppants can be transported to the fracture site more effectively than the high-density proppants.

Figure 3 shows the XRD patterns of the proppants with the different fly ash contents. It can be seen that all the proppants exhibited very similar crystalline phase compositions. The main phases are corundum $\left(\mathrm{Al}_{2} \mathrm{O}_{3}\right.$, PDF NO. 74-1081) and mullite $\left(\mathrm{Al}_{2}\left(\mathrm{Al}_{2.8} \mathrm{Si}_{1.2}\right) \mathrm{O}_{9.54}, \mathrm{PDF}\right.$ NO. 15-0776). As the fly ash content increased, the phase composition shows no obvious change and all of the phases indicate high crystallinity, but the relative amount of the mullite phase increases. That means a higher fly ash content favours the formation of the mullite phase. Furthermore, the crystalline phase containing manganese is not found in the XRD patterns, which is possibly due to the formation of a glass phase which is related to the manganese dioxide. These observations are in agreement with the findings of the previous studies that showed that the liquid phases can be formed at $1150{ }^{\circ} \mathrm{C}$ in the $\mathrm{MnO}-\mathrm{CaO}-\mathrm{Al}_{2} \mathrm{O}_{3}-\mathrm{SiO}_{2}$ system [20]. Another possible reason is that the added $\mathrm{MnO}_{2}$ entered the solid solution with the alumina and promoted the grain growth and the densification of the alumina [18].

Figure 4 shows the SEM images of the crystal composition and the microstructure of the proppants sintered for $120 \mathrm{~min}$ with the different fly ash contents. The crystal composition of the proppants was influenced by the fly ash content. The proppants with 10 wt. \% fly

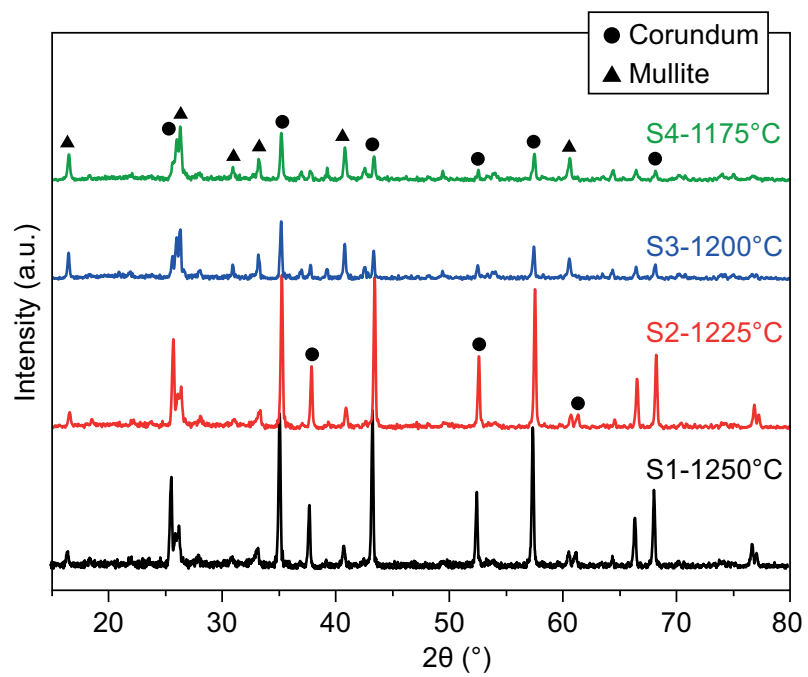

Figure 3. The XRD patterns of the proppants with the different fly ash contents. 
ash and sintered at $1250{ }^{\circ} \mathrm{C}$ (denoted as $\mathrm{S} 1-1250{ }^{\circ} \mathrm{C}$ ) had a denser microstructure with larger grain crystals (Figure 4a).

The proppants with $20 \mathrm{wt}$. \% fly ash and sintered at $1225^{\circ} \mathrm{C}$ (denoted as $\mathrm{S} 2-1225^{\circ} \mathrm{C}$ ) showed grain crystals and prismatic crystals (Figure 4b). Furthermore, as the fly ash content increased, the amount of prismatic crystals increased (Figures 4c, d). Figure 4e shows the EDS spectrum of the prismatic crystals in the proppants, which confirmed that they consisted of $\mathrm{Al}_{2} \mathrm{O}_{3}$ and $\mathrm{SiO}_{2}$. In addition, the $\mathrm{Al}_{2} \mathrm{O}_{3} / \mathrm{SiO}_{2}$ molar ratio of the crystals was 1.48 compared with the stoichiometric mullite $\left(\mathrm{Al}_{2} \mathrm{O}_{3} / \mathrm{SiO}_{2}=\right.$ $=1.5$ molar ratio). According to the XRD analysis results, these prismatic crystals should be mullite and the grain crystals should be corundum.

The results show that the addition of fly ash can promote the formation of prismatic mullite crystals. This can be attributed to two advantages. First, the addition of the fly ash reduces the formation temperature of the liquid phase, which is conducive to the formation of the mullite crystal nuclei [21, 22]. Second, the formation of the liquid phase is conducive to the growth of the

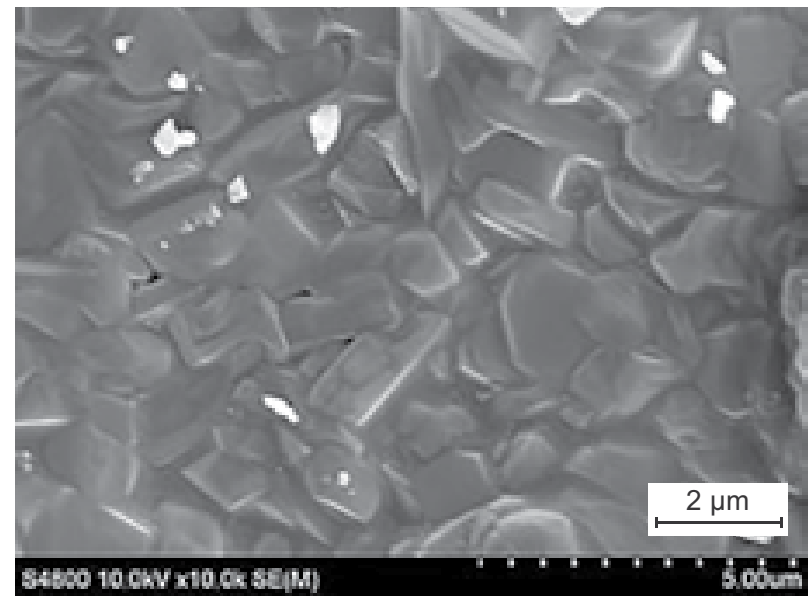

a) $\mathrm{S} 1-1250^{\circ} \mathrm{C}$

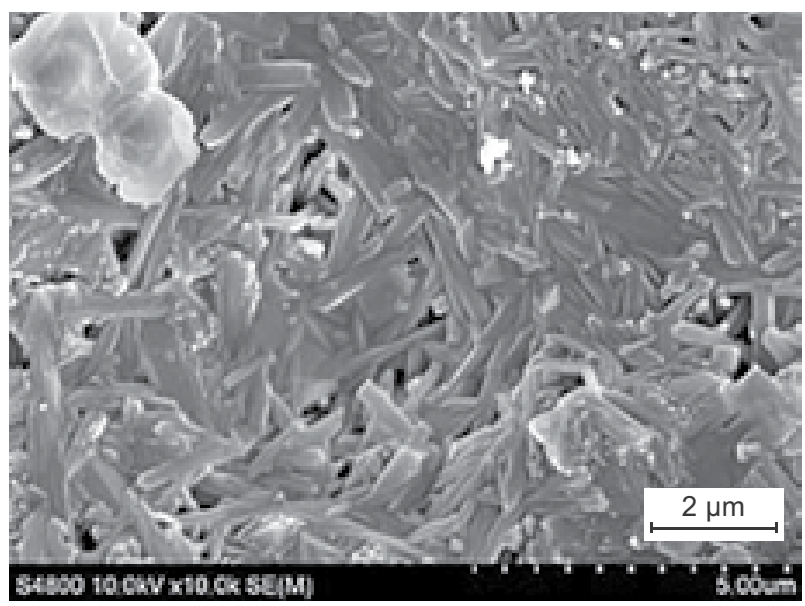

c) $\mathrm{S} 3-1200^{\circ} \mathrm{C}$ grains, due to the enhanced diffusion of the ions such as the $\mathrm{Al}^{3+}$ and $\mathrm{Si}^{4+}$ and the solution-precipitation in the glass $[15,23]$. It has been recognised that mullite formation in diphasic aluminosilicate gels or in reaction to the sintering couples of quartz and $\mathrm{Al}_{2} \mathrm{O}_{3}$ is controlled by the dissolution precipitation reactions, in which the $\mathrm{Al}_{2} \mathrm{O}_{3}$ component dissolves in the coexisting $\mathrm{SiO}_{2}$ liquid until a critical $\mathrm{Al}_{2} \mathrm{O}_{3}$ concentration is reached [24]. Furthermore, as previously reported, the synthesised mullite can be composed of any composition between $x=0$ (sillimanite) and $x=1$ (alumina) in the general formula $\mathrm{Al}_{4+2 x} \mathrm{Si}_{2-2 x} \mathrm{O}_{10-x}$, depending on the starting material and processing route $[23,25]$. That means that the $\mathrm{Al}_{2} \mathrm{O}_{3} / \mathrm{SiO}_{2}$ molar ratio is often less than 1.5. In this study, the orthorhombic type mullite prisms with an $\mathrm{Al}_{2} \mathrm{O}_{3} / \mathrm{SiO}_{2}$ molar ratio of 1.48 (Figure 4e) were prepared by using the initial $\mathrm{SiO}_{2}$-rich composition $\left(\mathrm{Al}_{2} \mathrm{O}_{3} / \mathrm{SiO}_{2}<\right.$ $<1.16$ molar ratio). This may be due to a mixture of the mullite prisms with the corundum grains, which will be averaged out in the EDS beam analysis in the SEM. Furthermore, the proppants with low density and high strength can be attributed to the interlocking structure

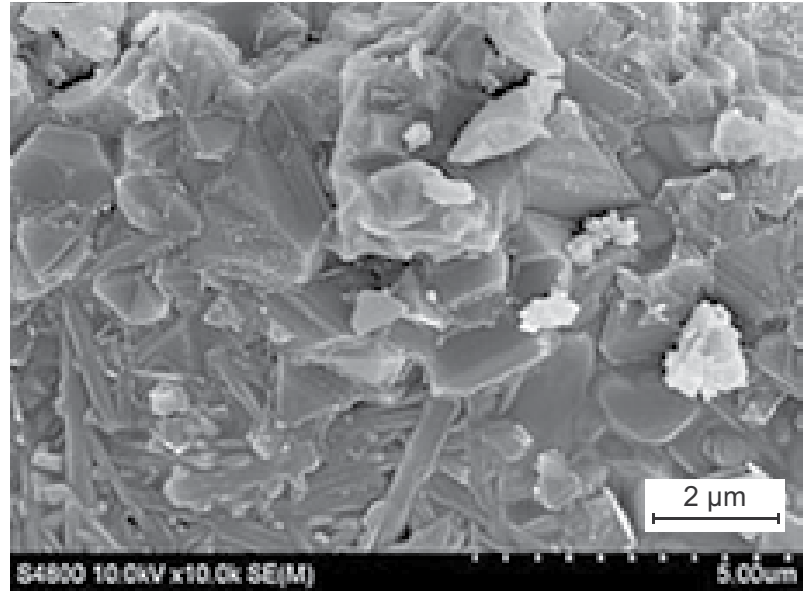

b) $\mathrm{S} 2-1225^{\circ} \mathrm{C}$

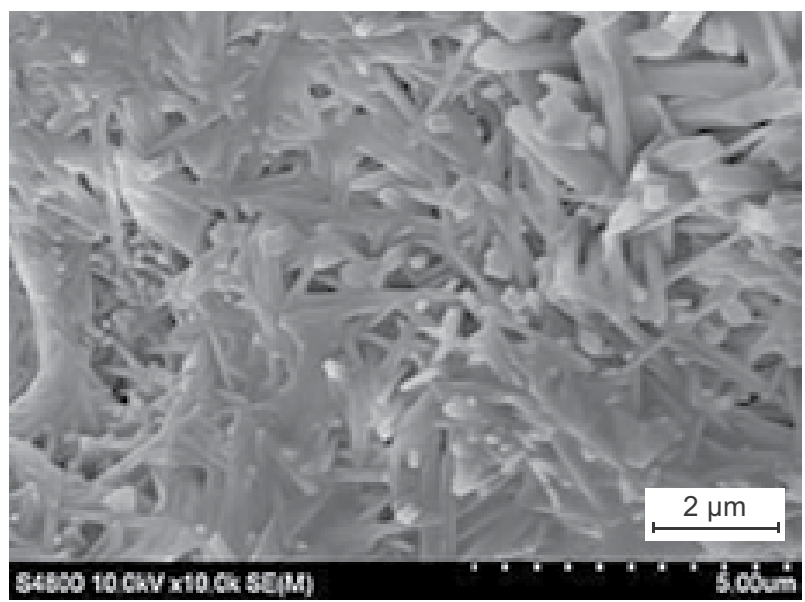

d) $\mathrm{S} 4-1175^{\circ} \mathrm{C}$

Figure 4. The SEM images of the different proppants after the acid corrosion: a) S1-1250 ${ }^{\circ} \mathrm{C}$, b) S2-1225 ${ }^{\circ} \mathrm{C}$, c) $\mathrm{S} 3-1200{ }^{\circ} \mathrm{C}$, d) $\mathrm{S} 4-1175^{\circ} \mathrm{C}$. (Continue on next page) 


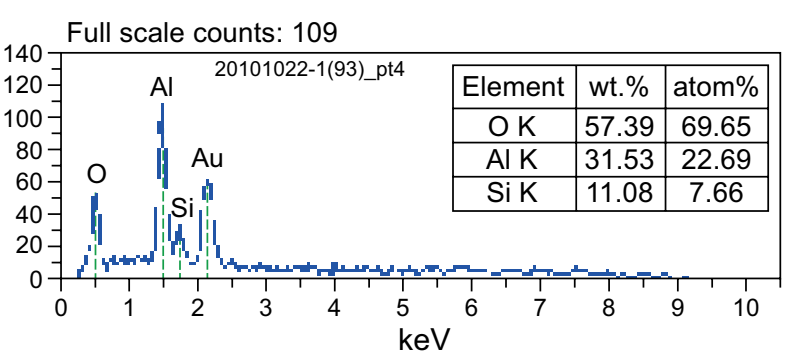

e)

Figure 4. The EDS analysis result of the region selected in the prismatic crystals (e).

constructed by the in situ synthesised mullite whiskers and corundum grains (Figure 4c), which is porous, but has a high mechanical strength [22].

Usually the purpose of the fracture surface analysis is to observe the fracture mode. The fracture mode depends upon the crystal structure, microstructure, reinforcement mode, size and shape of the component and loading conditions [26]. The volume-distributed flaws such as the pores, inclusions or compositional inhomogeneity all can lead to a fracture [27]. Figure 5 shows the SEM images of the different proppant fracture morphologies. The cracks, pores, and cleavage steps can be seen on the fracture surface. The fractures that moved through the grains (a transgranular fracture) or around the grains (an intergranular fracture) can be seen on these fracture surfaces.

The pores can reduce the density of the proppants and facilitate the transport with the fracturing fluids. However, the pores also limit the strength as defects. Figure 5 clearly shows many pores (big pores and small pores) on the fracture surfaces of the different proppants. It is well known that the porosity can be effectively controlled by varying the raw material components and sintering conditions such as the sintering temperature and dwelling time [28, 29]. Here, the pores are supposed to be produced by the addition of the fly ash which is composed of a lot of hollow glass balls. As the fly ash content increases, the porosity increases and the strength of the proppant decreases.

Figures $5 \mathrm{a}$ and $5 \mathrm{~b}$ shows the intergranular fracture mode where the crack takes the path along the grain boundaries between the grains. Also, the prismatic

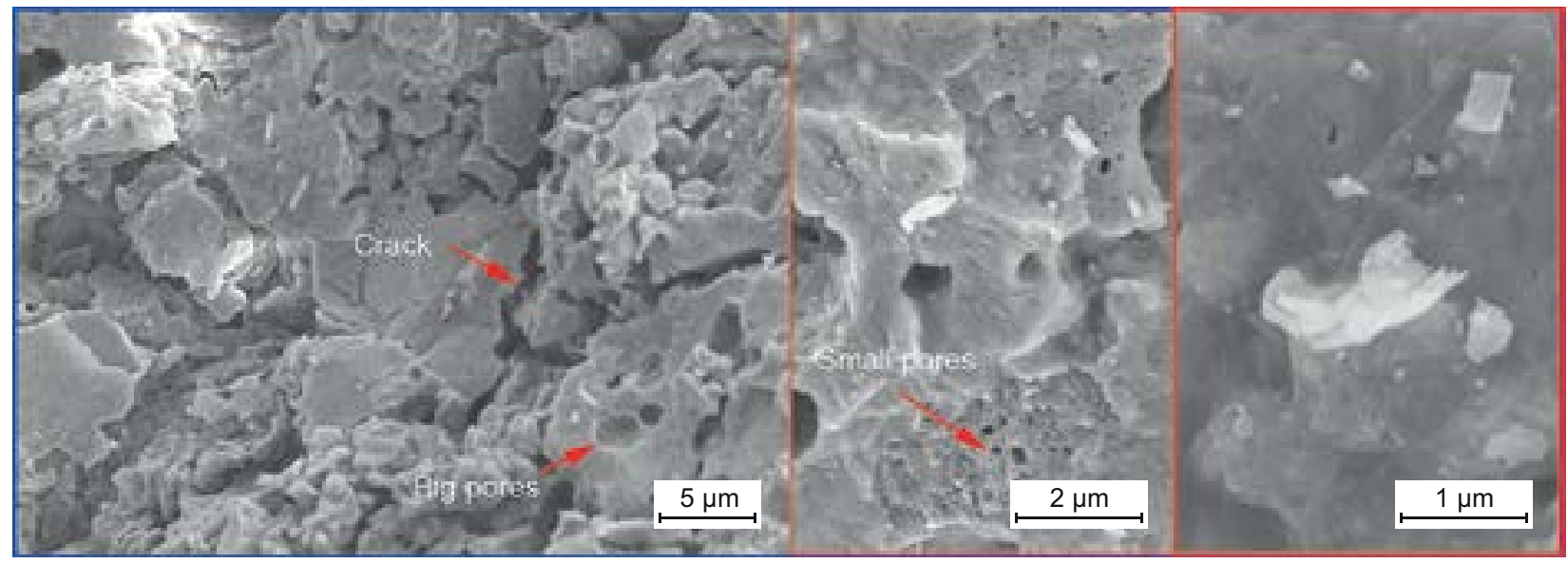

a) $\mathrm{S} 1-1250^{\circ} \mathrm{C}$

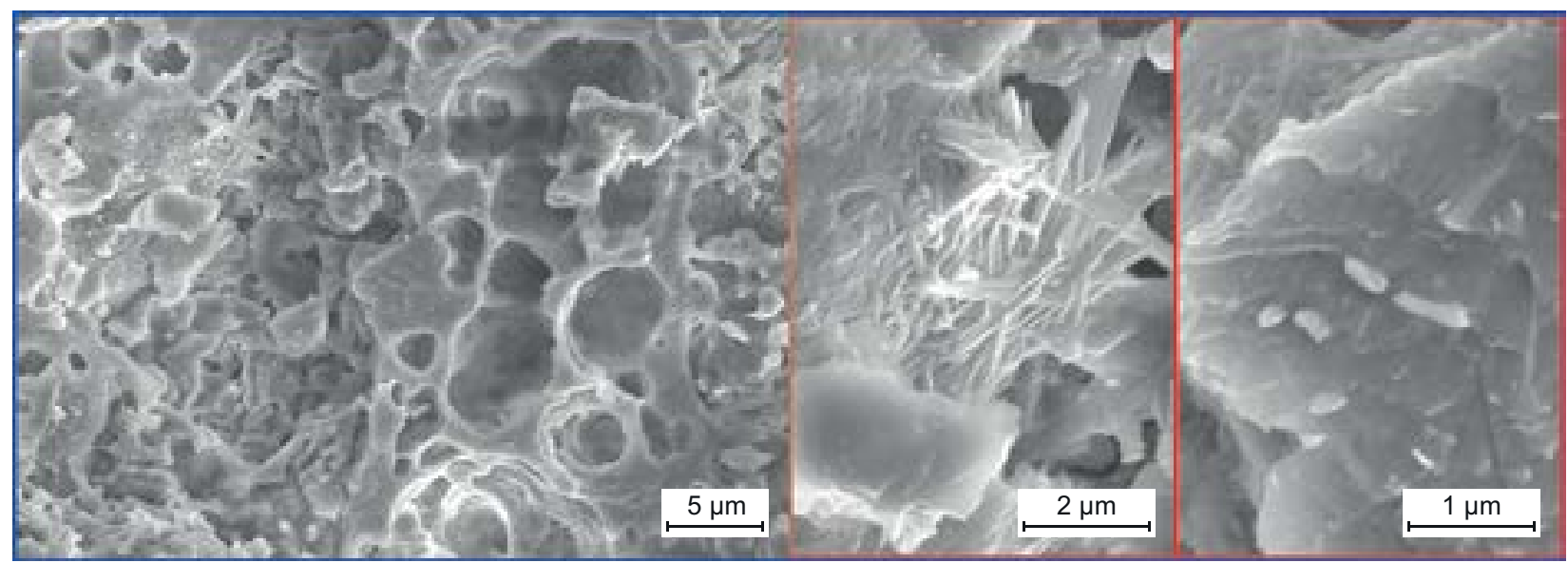

b) $\mathrm{S} 2-1225^{\circ} \mathrm{C}$

Figure 5. The SEM images of the fracture surfaces of the different proppants after the breakage ratio test: a) $\mathrm{S} 1-1250{ }^{\circ} \mathrm{C}$, b) $\mathrm{S} 2-1225^{\circ} \mathrm{C}$. (Continue on next page) 


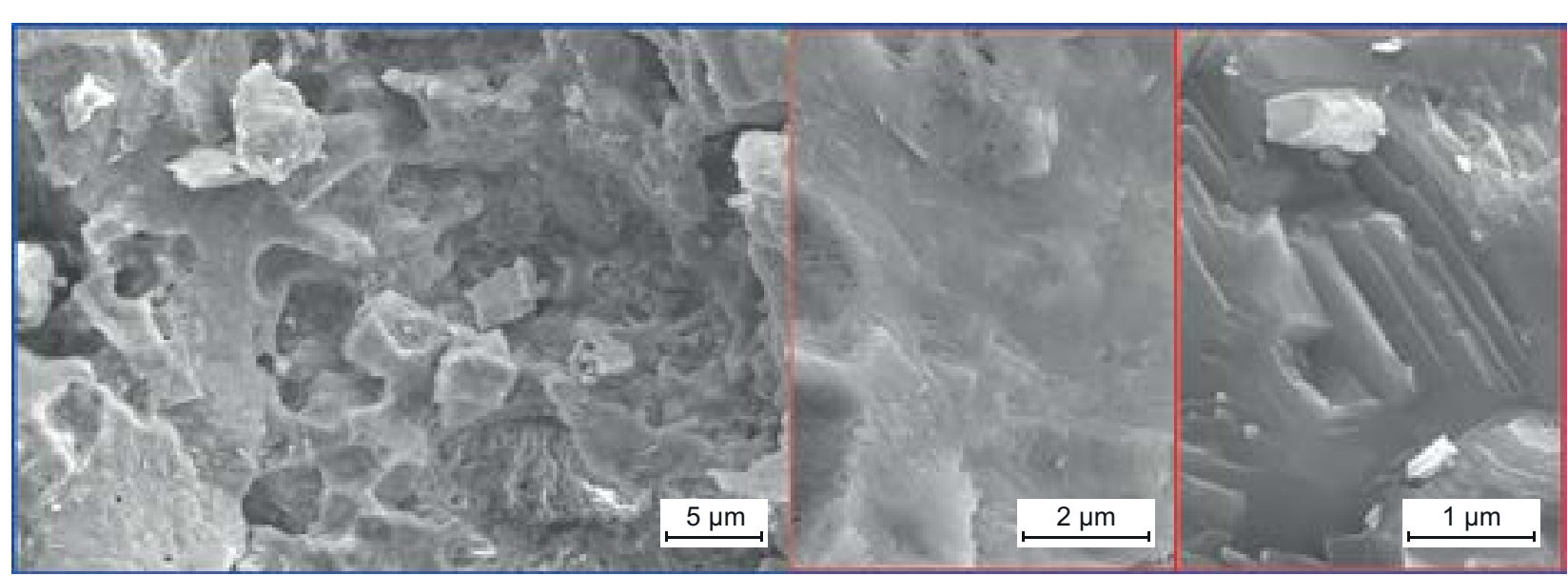

c) $\mathrm{S} 3-1200{ }^{\circ} \mathrm{C}$

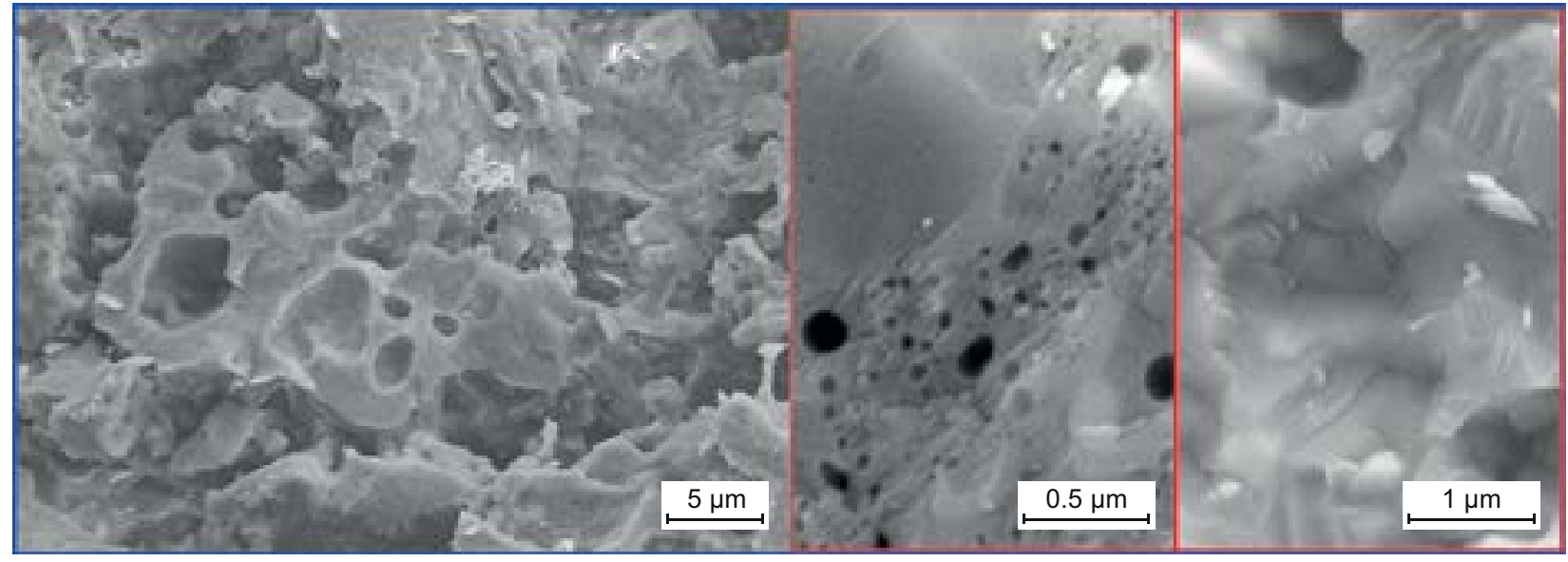

d) $\mathrm{S} 4-1175^{\circ} \mathrm{C}$

Figure 5. The SEM images of the fracture surfaces of the different proppants after the breakage ratio test: c) S3-1200 ${ }^{\circ} \mathrm{C}$, d) $\mathrm{S} 4-1175^{\circ} \mathrm{C}$.

mullite crystals embedded on the fracture surface are intact. Moreover, the crack encounters pores as it traversed through a proppant body. Figures $5 \mathrm{c}$ and $5 \mathrm{~d}$ clearly show much of the cleavage step hackle on those fracture surfaces. It is the transgranular fracture mode in which the crack propagates directly through the grains on the cleavage planes. That means that the cracks propagate through the prismatic mullite crystal. The prismatic mullite crystals, as reinforcing phases, have interconnected elongated-grain microstructures that reinforce the proppants, as shown in Figure 4. With the increase in the fly ash content, the amount of the prismatic mullite crystals increases, and the proportion of the intragranular fracture increases.

\section{CONCLUSIONS}

The low-temperature sintering of the bauxite-fly ashbased proppants was explored using dolomite and $\mathrm{MnO}_{2}$ as the additives. The addition of the fly ash effectively decreased the density and the sintering temperature of the proppants and caused a mullite phase to form. The density of the proppants decreased as the additional amount of fly ash increased. An appropriate amount of fly ash facilitated the sintering, decreased the densities, and improved the performance of the proppants. The highstrength proppants with a $30 \mathrm{wt} . \%$ fly ash content and sintered at $1200{ }^{\circ} \mathrm{C}$ met the requirements of the coalbed methane mining. The sintering temperatures used were significantly lower than those used in the previous studies $\left(>1300{ }^{\circ} \mathrm{C}\right)$. The low-density of the proppants and low energy consumption of the low-temperature sintering process used in their production makes them a strong candidate to be used as fracturing proppants in future applications.

\section{Acknowledgements}

This work was supported by the Fund for Shanxi Key Subjects Construction, Scientific Research Starting Foundation for Doctors of Taiyuan University of Science and Technology (20162006), Shanxi Province Science and Technology Major Special Project (20181101001), Key Research and Development (R\&D) Projects of Shanxi Province (201803D121027), and The National Nature Science Foundation of China (51802212) 


\section{REFERENCES}

1. Hammond P. S. (1995): Settling and slumping in a Newtonian slurry, and implications for proppant placement during hydraulic fracturing of gas wells. Chemical Engineering Science, 50, 3247-3260. doi: 10.1016/0009-2509 (95)00152-u.

2. Liang F., Sayed M., Al-Muntasheri G. A., Chang F. F., Li L. (2016): A comprehensive review on proppant technologies. Petroleum, 2, 26-39. doi: 10.1016/j.petlm.2015.11.001.

3. Gu M., Dao E., Mohanty K. K. (2015): Investigation of ultra-light weight proppant application in shale fracturing. Fuel, 150, 191-201. doi: 10.1016/j.fuel.2015.02.019.

4. Gaurav A. (2010). Ultra-light weight proppants in shale gas fracturing, University of Texas at Austin, Austin, Texas, USA.

5. Gaurav A., Dao E. K., Mohanty K. K. (2010). Ultra-Lightweight Proppants for Shale Gas Fracturing, in: Proceedings of Tight Gas Completions Conference, Society of Petroleum Engineers, San Antonio, Texas, USA. pp.13.

6. Zoveidavianpoor M., Gharibi A., bin Jaafar M. Z. (2018): Experimental characterization of a new high-strength ultralightweight composite proppant derived from renewable resources. Journal of Petroleum Science and Engineering, 170, 1038-1047. doi: 10.1016/j.petrol.2018.06.030.

7. Parse J. B., Jette B. D. (2015). Multiple component neutrally buoyant proppant. U.S. Patent No. 9,051,511 B2.

8. Parse J. B., Jette B. D. (2015). Single component neutrally buoyant proppant. U.S. Patent No. 9,102,867 B2.

9. Nadesan M. S., Dinakar P. (2017): Structural concrete using sintered flyash lightweight aggregate: A review. Construction and Building Materials, 154, 928-944. doi: 10.1016/j.conbuildmat.2017.08.005.

10. Kim J.-M., Kim H.-S. (2004): Glass-ceramic produced from a municipal waste incinerator fly ash with high $\mathrm{Cl}$ content Journal of the European Ceramic Society, 24, 2373-2382. doi: 10.1016/j.jeurceramsoc.2003.08.001.

11. Kumar S., Singh K. K., Ramachandrarao P. (2000): Synthesis of cordierite from fly ash and its refractory properties. Journal of Materials Science Letters, 19, 1263-1265. doi: 10.1023/A:1006737932563.

12. Dong Y., Hampshire S., Zhou J. E., Lin B., Ji Z., Zhang X., Meng G. (2010): Recycling of fly ash for preparing porous mullite membrane supports with titania addition. Journal of Hazardous Materials, 180, 173-80. doi: 10.1016/j.jhazmat. 2010.04.010.

13. Dong Y., Liu X., Ma Q., Meng G. (2006): Preparation of cordierite-based porous ceramic micro-filtration membranes using waste fly ash as the main raw materials. Journal of Membrane Science, 285, 173-181. doi: 10.1016/j.memsci. 2006.08.032.

14. Chen X., Li T., Ren Q., Wu X., Li H., Dang A., Zhao T., Shang Y., Zhang Y. (2017): Mullite whisker network reinforced ceramic with high strength and lightweight. Journal of Alloys and Compounds, 700, 37-42. doi: 10.1016/ j.jallcom.2017.01.075.

15. Wu X., Huo Z., Ren Q., Li H., Lin F., Wei T. (2017): Preparation and characterization of ceramic proppants with low density and high strength using fly ash. Journal of Alloys and Compounds, 702, 442-448. doi: 10.1016/j.jallcom. 2017.01.262.
16. Hao J., Ma H., Feng X., Gao Y., Wang K., Tian Y. (2018): Low-temperature sintering of ceramic proppants by adding solid wastes. International Journal of Applied Ceramic Technology, 15, 563-568. doi: 10.1111/ijac.12818.

17. Liu Z., Zhao J., Li Y., Zeng Z., Mao J., Peng Y., He Y. (2016): Low-temperature sintering of bauxite-based fracturing proppants containing $\mathrm{CaO}$ and $\mathrm{MnO}_{2}$ additives. Materials Letters, 171, 300-303. doi: 10.1016/j.matlet.2016.02.090.

18. Erkalfa H., Misirli Z., Baykara T. (1998): The effect of $\mathrm{TiO}_{2}$ and $\mathrm{MnO}_{2}$ on densification and microstructural development of alumina. Ceramics International, 24, 81-90. doi: 10.1016/s0272-8842(97)00082-5.

19. Zhao J., Liu Z., Li Y. (2015): Preparation and characterization of low-density mullite-based ceramic proppant by a dynamic sintering method. Materials Letters, 152, 72-75. doi: 10.1016/j.matlet.2015.03.060.

20. Roghani G., Jak E., Hayes P. (2003): Phase-equilibrium data and liquidus for the system "MnO" $-\mathrm{CaO}-\mathrm{Al}_{2} \mathrm{O}_{3}-\mathrm{SiO}_{2}$ at $\mathrm{Al}_{2} \mathrm{O}_{3} / \mathrm{SiO}_{2}$ of 0.55 and 0.65. Metallurgical and Materials Transactions B, 34, 173-182. doi: 10.1007/s11663-0030004-2.

21. Hirata Y., Matsushita S., Ishihara Y., Katsuki H. (1991): Colloidal Processing and Mechanical Properties of Whisker-Reinforced Mullite Matrix Composites. Journal of the American Ceramic Society, 74, 2438-2442. doi: 10.1111/ j.1151-2916.1991.tb06781.x.

22. Li S., Du H., Guo A., Xu H., Yang D. (2012): Preparation of self-reinforcement of porous mullite ceramics through in situ synthesis of mullite whisker in flyash body. Ceramics International, 38, 1027-1032. doi: 10.1016/j.ceramint.2011. 08.026.

23. Park Y. M., Yang T. Y., Yoon S. Y., Stevens R., Park H. C. (2007): Mullite whiskers derived from coal fly ash. Materials Science and Engineering: A, 454-455, 518-522. doi: 10.1016/j.msea.2006.11.114.

24. Kong L. B., Huang H., Zhang T. S., Gan Y. B., Ma J., Boey F., Zhang R. F. (2003): Effect of transition metal oxides on mullite whisker formation from mechanochemically activated powders. Materials Science and Engineering: A, 359, 75-81. doi:10.1016/s0921-5093(03)00381-2.

25. Souza M. F., Yamamoto J., Regiani I., Paiva-Santos C. O., Souza D. P. F. (2000): Mullite Whiskers Grown from ErbiaDoped Aluminum HydroxideSilica Gel. Journal of the American Ceramic Society, 83, 60-64. doi: 10.1111/j.11512916.2000.tb01148.x.

26. Becker W.T. L. S. (2002). Fracture Appearance and Mechanisms of Deformation and Fracture ed., pp.559-586, ASM International, doi: 10.31399/asm.hb.v11.a0003537.

27. Quinn G. D. (2016). NIST Recommended Practice Guide Fractography of Ceramics and Glasses. $2^{\text {nd }}$ ed., National Institute of Standards and Technology, doi: 10.6028/NIST. SP.960-16e2.

28. Zhu L., Dong Y., Hampshire S., Cerneaux S., Winnubst L. (2015): Waste-to-resource preparation of a porous ceramic membrane support featuring elongated mullite whiskers with enhanced porosity and permeance. Journal of the European Ceramic Society, 35, 711-721. doi: 10.1016/j. jeurceramsoc.2014.09.016.

29. She J. H., Ohji T. (2003): Fabrication and characterization of highly porous mullite ceramics. Materials Chemistry and Physics, 80, 610-614. doi:10.1016/s0254-0584(03) 00080-4. 